\title{
Resultat ausserordentliche Neuwahl FMH Services Genossenschaft
}

Geschätzte Genossenschafterinnen und

Genossenschafter

Infolge des statutarisch bedingten Rücktritts per Ende 2015 von Dr. med. Max Giger wurde die Neuwahl eines Vertreters der FMH als Mitglied der Verwaltung der FMH Services Genossenschaft notwendig.

Wir freuen uns, Ihnen das Resultat der Wahl mitteilen zu dürfen.

Freundliche Grüsse

FMH Services Genossenschaft

Dr. med. Max Giger, Präsident der Verwaltung FMH Services

Beat Bär, Geschäftsführer FMH Services

\section{Ausserordentliche Neuwahl}

\section{Stimmabgabe}

21. Oktober - 30. November 2015 schriftlich bei der Gemeinde Oberkirch

\section{Auszählung}

Herr J. R. Rogger, Gemeindeverwaltung Oberkirch

3. Resultat

\subsection{Antrag 1}

Stimmen Sie der Wahl von Herrn Dr. med. Remo Osterwalder (neu) als Mitglied der Verwaltung der FMH Services zu?

\begin{tabular}{ll} 
Abgegebene Stimmen & 2602 \\
Ungültige Stimmen & 63 \\
Leere und keine Stimmen & 31 \\
Gültige Stimmen & 2508 \\
\hline JA-Stimmen & \\
NEIN-Stimmen & $\mathbf{2 4 0 2}$ \\
& $\mathbf{1 0 6}$
\end{tabular}

Dem Antrag 1 wird somit deutlich zugestimmt.

Das Ergebnis dieser Neuwahl wurde von J. R. Rogger, c/o Gemeindeverwaltung Oberkirch, am 2. Dezember 2015 als vollständig und richtig bestätigt.

\section{Résultat de l'élection extraordinaire de la société coopérative \\ FMH Services}

\section{Résultat}

En raison de la démission du Dr Max Giger fin 2015 pour des raisons statutaires, l'élection d'un nouveau délégué de la FMH comme membre du conseil d'administration de la société coopérative FMH Services s'est imposée. Aujourd'hui, nous avons le plaisir de vous annoncer le résultat.

Dr med. Max Giger, Président du conseil d'administration, Beat Bär, Directeur de FMH Services

\section{Election extraordinaire}

1. Remise des bulletins de vote

Du 21 octobre au 30 novembre 2015 par écrit auprès de la commune d'Oberkirch

\section{Dépouillement}

M. J. R. Rogger, commune d'Oberkirch

\subsection{Proposition $n^{\circ} 1$}

Acceptez-vous de nommer Monsieur le Docteur med. Remo Osterwalder (nouveau) comme membre du conseil d'administration de FMH Services ?

\begin{tabular}{ll}
\hline Bulletins de vote reçus & 2602 \\
Bulletins invalides & 63 \\
Bulletins vides ou pas de bulletin & 31 \\
Bulletins valables & 2508 \\
\hline Oui & \\
Non & $\mathbf{2 4 0 2}$ \\
\end{tabular}

La proposition $\mathrm{n}^{\circ} 1$ est ainsi approuvée à une large majorité.

Le résultat de l'élection a été confirmé le 2 décembre 2015 par J. R. Rogger, c/o administration communale d'Oberkirch, comme étant correct et exhaustif. 